\title{
Electronically Controllable Explicit Current Output Sinusoidal Oscillator Employing Single VDTA
}

\author{
Dinesh Prasad and D. R. Bhaskar \\ Department of Electronics \& Communication Engineering, Faculty of Engineering and Technology, Jamia Millia Islamia, \\ New Delhi 110025, India \\ Correspondence should be addressed to D. R. Bhaskar, dbhaskar@jmi.ac.in
}

Received 27 July 2012; Accepted 16 August 2012

Academic Editors: S. Gift, M. Liao, and L. Martiradonna

Copyright () 2012 D. Prasad and D. R. Bhaskar. This is an open access article distributed under the Creative Commons Attribution License, which permits unrestricted use, distribution, and reproduction in any medium, provided the original work is properly cited.

\begin{abstract}
A new current-mode sinusoidal oscillator employing a single voltage differencing transconductance amplifier (VDTA), two grounded capacitors, and one grounded resistor has been proposed. The proposed sinusoidal oscillator offers the following advantageous features: (i) use of grounded capacitors which are attractive from the view point of IC implementation as well as eliminating/accommodating parasitic capacitances, (ii) independent control of frequency of oscillation and condition of oscillation, (iii) ready availability of explicit current-mode output, (iv) low active and passive sensitivities, and (v) a very good frequency stability. The workability of the proposed configuration has been established by PSPICE simulations.
\end{abstract}

\section{Introduction}

In the synthesis of signal processing/signal generation circuits, current-mode $(\mathrm{CM})$ operation has received much attention over the conventional voltage-mode (VM) operation due to its wider bandwidth and high linearity [1]. There is a growing interest in the realization of sinusoidal oscillators with explicit $\mathrm{CM}$ output because these oscillators may be employed as test signal generators for the testing of $\mathrm{CM}$ filters, $\mathrm{CM}$ precision rectifier, and so forth, which would otherwise require additional voltage to current converter when tested by using conventional VM oscillators [2]. Sinusoidal oscillators find numerous applications in communication, control systems, signal processing, instrumentation, and measurement systems; see [3-5] and the references cited therein. Explicit current-mode sinusoidal oscillators (ECMSOs) based upon different active single building blocks are available in the literature; see [6-13] and the references cited therein.

In [14], many active building blocks have been introduced, VDTA is one of them. Although a CMOS realization of VDTA and its RF filter application has been introduced in [15], to the best knowledge and belief of the authors no other application has been reported in the open literature so far. Therefore, the purpose of this paper is to propose a new ECMSO using a single VDTA along with three passive components (two grounded capacitors and one grounded resistor), which offers (i) use of grounded capacitors which are attractive from the viewpoint of IC implementation as well as eliminating/accommodating parasitic capacitances, (ii) independent control of frequency of oscillation and condition of oscillation (iii) ready availability of explicit currentmode output, (iv) low active and passive sensitivities, and (v) a very good frequency stability. Apart from realizing the intended type of ECMSO, the proposed topology has other modes of operation also. The workability of the new circuit has been verified by PSPICE simulations.

\section{The New Oscillator Configuration}

The symbolic notation of the VDTA is shown in Figure 1, where $V_{P}$ and $V_{N}$ are input terminals and $Z, X^{+}$, and $X^{-}$ are the output terminals. All terminals of VDTA exhibit high 
impedance values [15]. The VDTA can be described by the following set of equations:

$$
\left[\begin{array}{c}
I_{Z} \\
I_{X^{+}} \\
I_{X^{-}}
\end{array}\right]=\left[\begin{array}{ccc}
g_{m_{1}} & -g_{m_{1}} & 0 \\
0 & 0 & g_{m_{2}} \\
0 & 0 & -g_{m_{2}}
\end{array}\right]\left[\begin{array}{c}
V_{V_{P}} \\
V_{V_{N}} \\
V_{Z}
\end{array}\right] .
$$

A routine circuit analysis yields the following characteristic equation:

$$
s^{2}+s \frac{1}{C_{1}}\left(\frac{1}{R_{1}}-g_{m_{1}}\right)+\frac{g_{m_{1}} g_{m_{2}}}{C_{1} C_{2}}=0 .
$$

Thus, the condition of oscillation (CO) and frequency of oscillation (FO) are given by

$$
\begin{aligned}
& \left(\frac{1}{R_{1}}-g_{m_{1}}\right) \leq 0, \\
& \omega_{0}=\sqrt{\frac{g_{m_{1}} g_{m_{2}}}{C_{1} C_{2}} .}
\end{aligned}
$$

Therefore, it is seen that CO can independently be controlled by resistor $R_{1}$ while FO is electronically controllable by transconductance $g_{m_{2}}$.

With the feedback link broken at node " $P$ " and considering the $V_{P}$ terminal of VDTA as the input, the two open loop transfer functions realized by the proposed circuit are given by

$$
\begin{aligned}
& \frac{V_{0_{a}}}{V_{\text {in }}}=\frac{g_{m_{1}} g_{m_{2}} / C_{1} C_{2}}{s^{2}+s\left(1 / R_{1} C_{1}\right)+g_{m_{1}} g_{m_{2}} / C_{1} C_{2}}, \\
& \frac{V_{0_{b}}}{V_{\text {in }}}=\frac{s\left(g_{m_{1}} / C_{1}\right)}{s^{2}+s\left(1 / R_{1} C_{1}\right)+g_{m_{1}} g_{m_{2}} / C_{1} C_{2}} .
\end{aligned}
$$

Thus, in this mode, the same configuration can be used to realize low-pass and band-pass filters simultaneously. From $(4)$, the natural frequency $\left(\omega_{0}\right)$ and bandwidth (BW) are given by

$$
\begin{gathered}
\omega_{0}=\sqrt{\frac{g_{m_{1}} g_{m_{2}}}{C_{1} C_{2}}}, \\
\mathrm{BW}=\frac{1}{R_{1} C_{1}} .
\end{gathered}
$$

Thus, it is seen that $\omega_{0}$ and BW are independently tunable.

In the third mode of operation, the current transfer functions obtained from Figure 2 are given by

$$
\begin{gathered}
\frac{I_{0}(s)}{I_{01}(s)}=-\frac{g_{m_{2}}}{s C_{1}}, \\
\frac{I_{02}(s)}{I_{01}(s)}=\frac{g_{m_{2}}}{s C_{1}}, \\
\frac{I_{03}(s)}{I_{01}(s)}=\frac{1}{s C_{1} R_{1}} .
\end{gathered}
$$

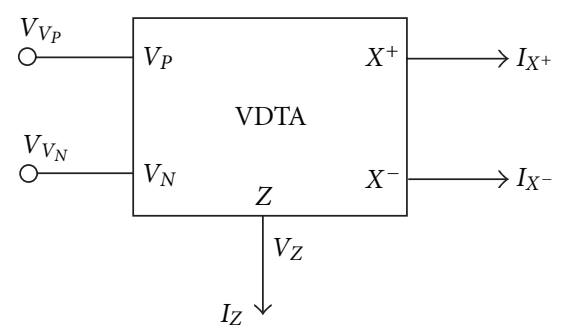

Figure 1: The symbolic notation of VDTA.

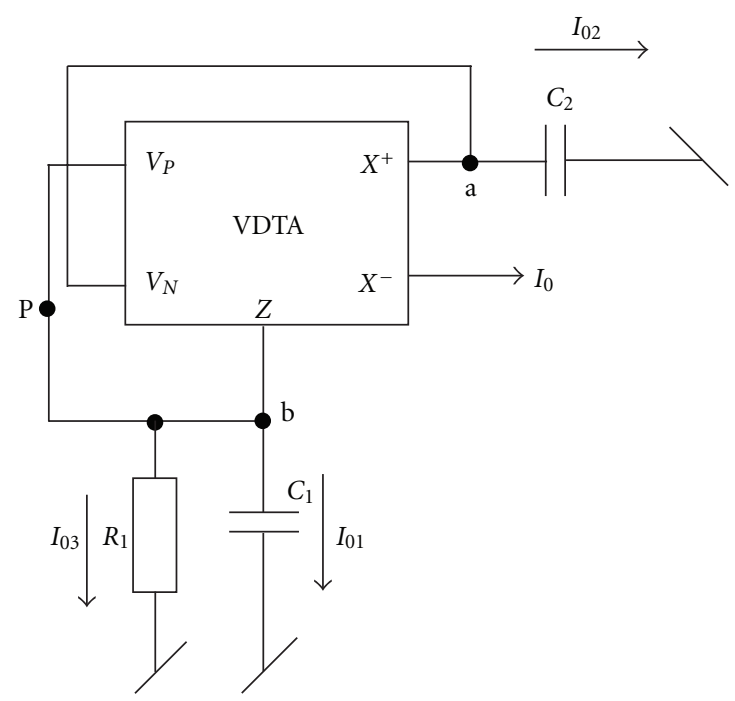

FIgURE 2: The proposed configuration.

For sinusoidal steady state, (6) becomes

$$
\begin{gathered}
\frac{I_{0}(j \omega)}{I_{01}(j \omega)}=\frac{g_{m_{2}}}{\omega C_{1}} e^{j 90^{\circ}}, \\
\frac{I_{02}(j \omega)}{I_{01}(j \omega)}=\frac{g_{m_{2}}}{\omega C_{1}} e^{-j 90^{\circ}}, \\
\frac{I_{03}(j \omega)}{I_{01}(j \omega)}=\frac{1}{\omega C_{1} R_{1}} e^{-j 90^{\circ}} .
\end{gathered}
$$

Thus, the phase difference $\phi$ between $\left(I_{0}\right.$ and $\left.I_{01}\right)$ is $90^{\circ}$ and between $\left(I_{02}\right.$ and $\left.I_{01}\right)$, and $\left(I_{03}\right.$ and $\left.I_{01}\right)$ is $-90^{\circ}$.

Hence, the currents $\left(I_{0}\right.$ and $\left.I_{01}\right),\left(I_{02}\right.$ and $\left.I_{01}\right)$ and $\left(I_{03}\right.$ and $\left.I_{01}\right)$ are in the quadrature form. To extract the currents $I_{01}, I_{02}$ and $I_{03}$ explicitly another device with their inputs virtually grounded will be required due to which although the capacitors $C_{1}, C_{2}$ and resistor $R_{1}$ will not be physically connected to ground but they will still be virtually grounded [16].

\section{Nonideal Analysis}

It is useful to count the effect of various VDTA nonideal parameters on the $\mathrm{CO}$ and $\mathrm{FO}$ of the proposed oscillator. Taking into account the finite $P$-terminal parasitic impedance consisting of a resistance $R_{P}$ in parallel with 


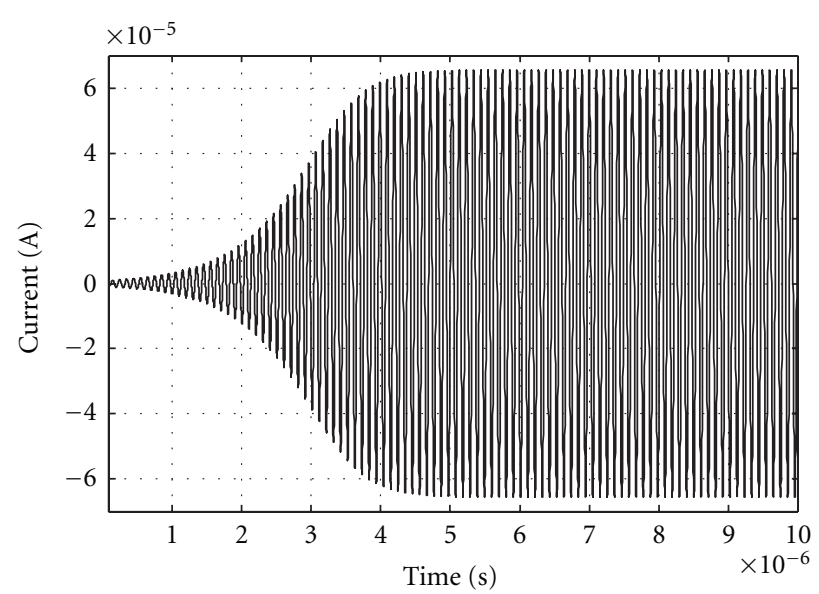

(a)

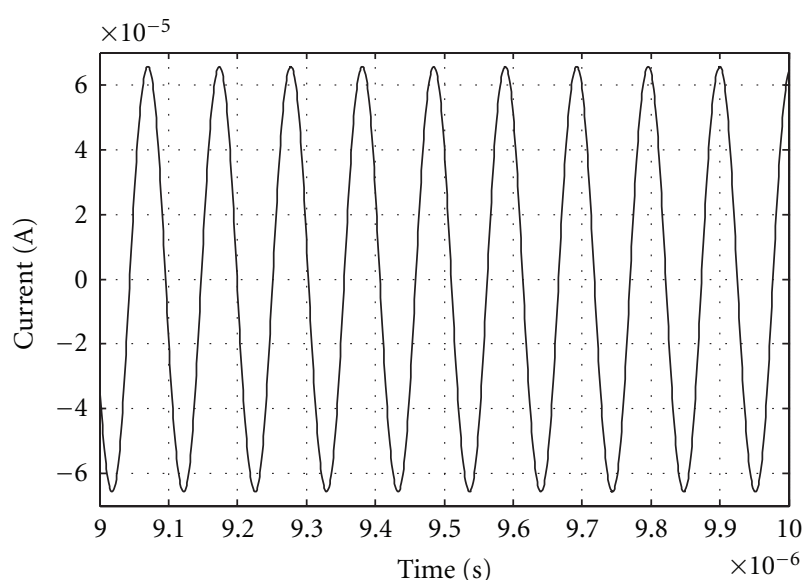

(b)

FIgURE 3: (a) Transient output waveform. (b) Steady-state response of the output.

TABLE 1

\begin{tabular}{|c|c|c|c|c|c|c|}
\hline $\begin{array}{l}\text { Active } \\
\text { component }\end{array}$ & $\begin{array}{l}\text { Grounded } \\
\text { capacitors }\end{array}$ & $\begin{array}{c}\text { Floating } \\
\text { capacitors }\end{array}$ & Resistors & $\begin{array}{l}\text { Availability of explict } \\
\text { current-mode output }\end{array}$ & $\begin{array}{l}\text { Electronic } \\
\text { tunability }\end{array}$ & Reference \\
\hline 1 & 3 & 0 & 5 & Yes & No & \multirow{4}{*}[8]{} \\
\hline 1 & 2 & 1 & 4 & Yes & No & \\
\hline 1 & 1 & 2 & 4 & Yes & No & \\
\hline 1 & 1 & 1 & 5 & Yes & No & \\
\hline 1 & 2 & 0 & 3 & Yes & No & [9] \\
\hline 1 & 2 & 0 & 3 & Yes & No & {$[10]$} \\
\hline 1 & 0 & 3 & 3 & Yes & No & \multirow[b]{2}{*}[11]{} \\
\hline 1 & 1 & 2 & 3 & Yes & No & \\
\hline 1 & 2 & 0 & 3 & Yes & No & {$[12]$} \\
\hline 1 & 0 & 2 & 5 & Yes & No & {$[13]$} \\
\hline 1 & 2 & 0 & 1 & Yes & Yes & Proposed \\
\hline
\end{tabular}

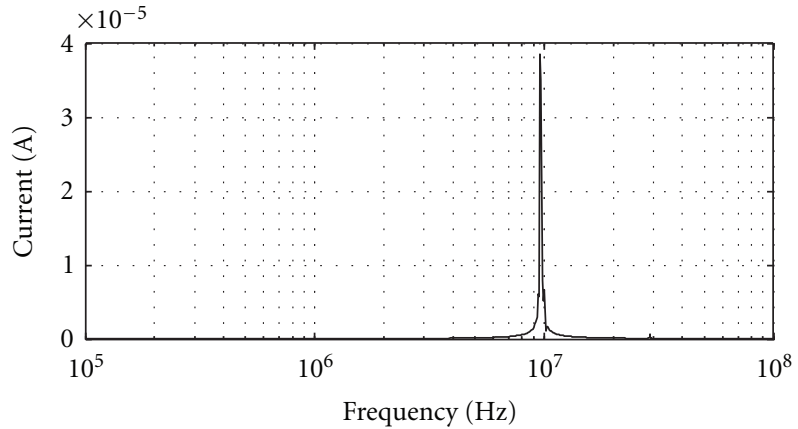

fosc $($ theoretical $)=10 \mathrm{MHz}$

fosc $($ practical $)=9.957 \mathrm{MHz}$

$\mathrm{THD}=2.66 \%$

Figure 4: Simulation result of the output spectrum.

capacitance $C_{P}$, the finite $N$-terminal parasitic impedance consisting of a resistance $R_{N}$ in parallel with capacitance

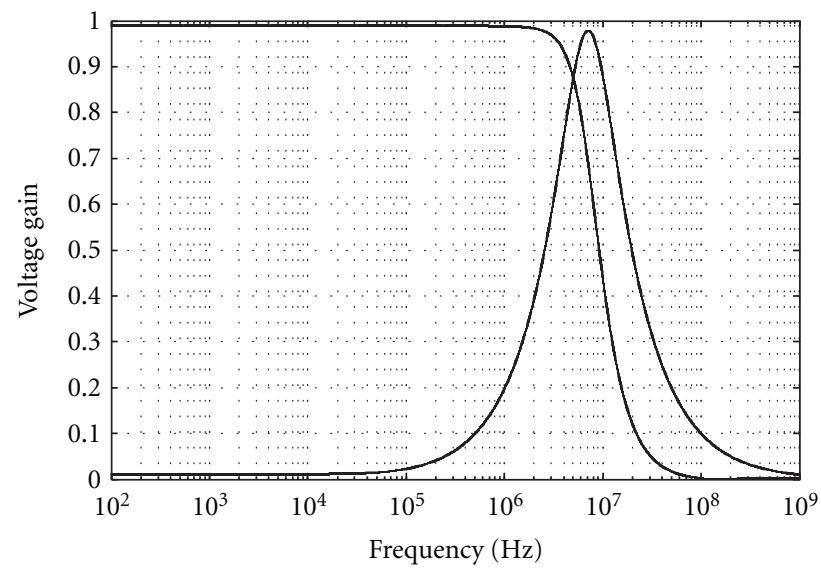

FIGURE 5: Frequency response of LP and BP filters.

$C_{N}$, the finite $X$-terminal parasitic impedance consisting of a resistance $R_{X}$ in parallel with capacitance $C_{X}$ and the parasitic impedance at the $Z$-terminal consisting of a 


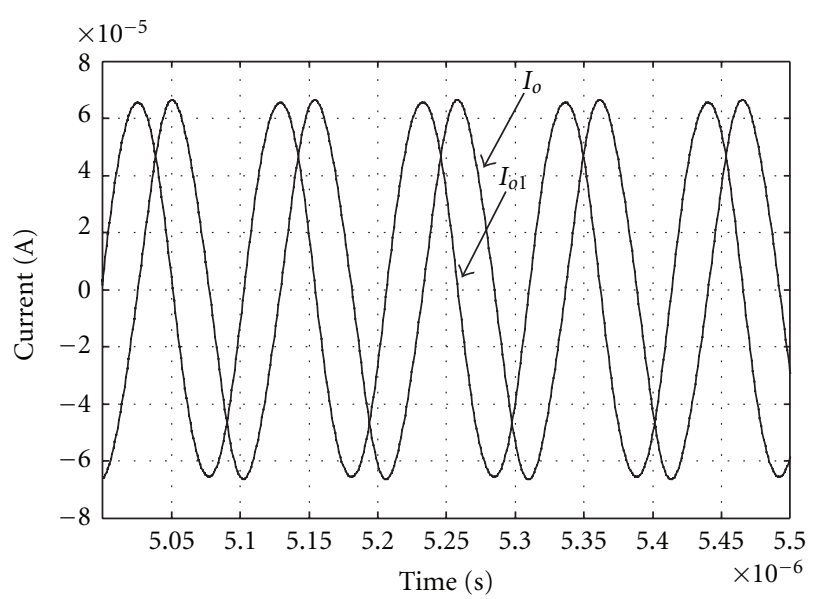

FIGURE 6: Steady-state response of the quadrature outputs of $I_{0}$ and $I_{01}$.

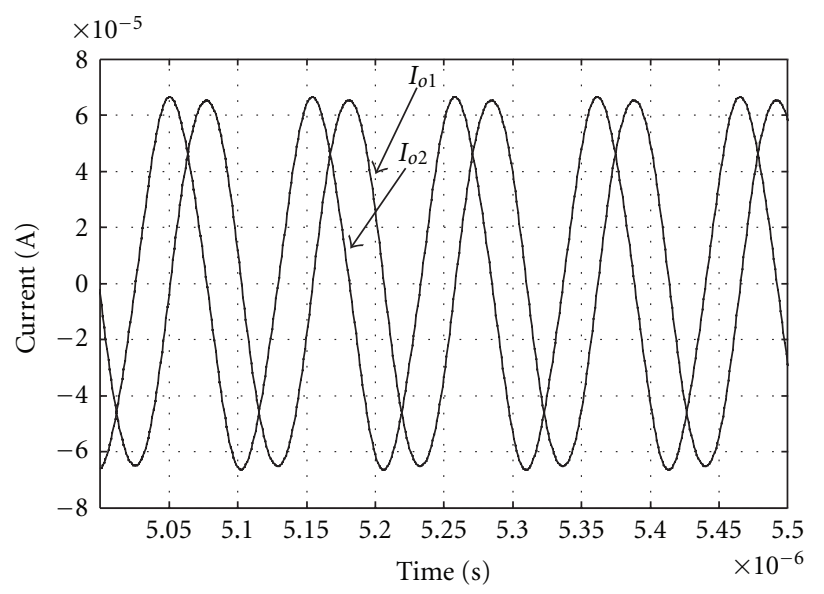

FIGURE 7: Steady-state response of the quadrature outputs of $I_{01}$ and $I_{02}$.

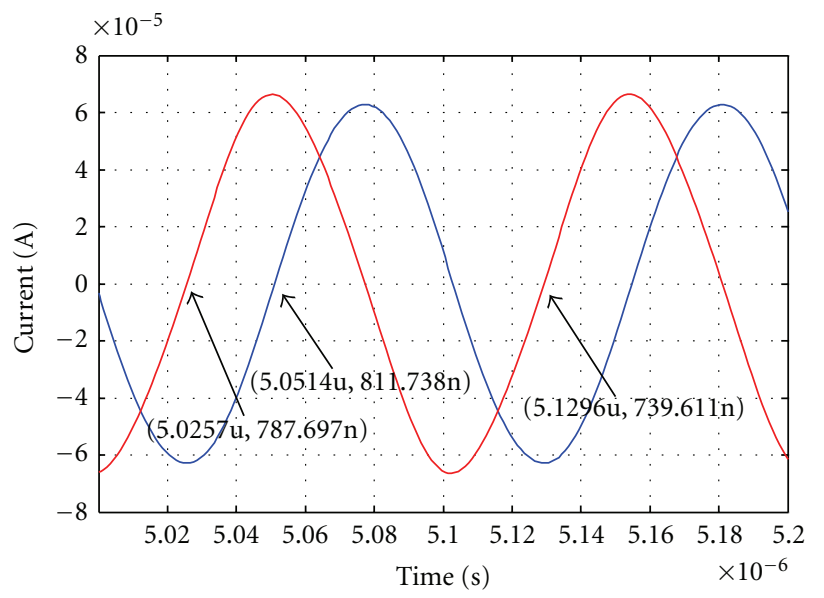

FIGURE 8: Steady-state response of the quadrature outputs of $I_{03}$ and $I_{01}$. resistance $R_{Z}$ in parallel with capacitance $C_{Z}$, then the nonideal expression of $\mathrm{CO}$ and $\mathrm{FO}$ can be given by

$$
\begin{gathered}
\frac{\left(1 / R_{X}+1 / R_{N}\right)}{\left(C_{2}+C_{X}+C_{N}\right)}+\frac{\left(1 / R_{1}+1 / R_{Z}+1 / R_{P}-g_{m_{1}}\right)}{\left(C_{1}+C_{Z}+C_{P}\right)} \leq 0, \\
\omega_{0}=\sqrt{\frac{g_{m_{1}} g_{m_{2}}+\left(1 / R_{X}+1 / R_{N}\right) \mathcal{R}}{\left(C_{1}+C_{Z}+C_{P}\right)\left(C_{2}+C_{X}+C_{N}\right)}},
\end{gathered}
$$

where $\mathcal{R}$ denotes $\left(1 / R_{1}+1 / R_{Z}+1 / R_{P}-g_{m_{1}}\right)$, then, the active and passive sensitivities of $\omega_{0}$ can be found as

$$
\begin{aligned}
& S_{C_{1}}^{\omega_{0}}=-\frac{C_{1}}{2\left(C_{1}+C_{Z}+C_{P}\right)}, \\
& S_{C_{Z}}^{\omega_{0}}=-\frac{C_{Z}}{2\left(C_{1}+C_{Z}+C_{P}\right)}, \\
& S_{C_{1}}^{\omega_{0}}=-\frac{C_{P}}{2\left(C_{1}+C_{Z}+C_{P}\right)}, \\
& S_{C_{2}}^{\omega_{0}}=-\frac{C_{2}}{2\left(C_{2}+C_{X}+C_{N}\right)}, \\
& S_{C_{X}}^{\omega_{0}}=-\frac{C_{X}}{2\left(C_{2}+C_{X}+C_{N}\right)}, \\
& S_{C_{X}}^{\omega_{0}}=-\frac{C_{N}}{2\left(C_{2}+C_{X}+C_{N}\right)}, \\
& S_{R_{1}}^{\omega_{0}}=-\frac{\left(1 / R_{X}+1 / R_{N}\right)}{2 R_{1}\left\{g_{m_{1}} g_{m_{2}}+\left(1 / R_{X}+1 / R_{N}\right) \mathcal{R}\right\}}, \\
& S_{R_{Z}}^{\omega_{0}}=-\frac{\left(1 / R_{X}+1 / R_{N}\right)}{2 R_{Z}\left\{g_{m_{1}} g_{m_{2}}+\left(1 / R_{X}+1 / R_{N}\right) \mathcal{R}\right\}}, \\
& S_{R_{P}}^{\omega_{0}}=-\frac{\left(1 / R_{X}+1 / R_{N}\right)}{2 R_{P}\left\{g_{m_{1}} g_{m_{2}}+\left(1 / R_{X}+1 / R_{N}\right) \mathcal{R}\right\}}, \\
& S_{R_{X}}^{\omega_{0}}=-\frac{\left(1 / R_{1}+1 / R_{Z}+1 / R_{P}-g_{m_{1}}\right)}{2 R_{X}\left\{g_{m_{1}} g_{m_{2}}+\left(1 / R_{X}+1 / R_{N}\right) \mathcal{R}\right\}}, \\
& S_{R_{N}}^{\omega_{0}}=-\frac{\left(1 / R_{1}+1 / R_{Z}+1 / R_{P}-g_{m_{1}}\right)}{2 R_{N}\left\{g_{m_{1}} g_{m_{2}}+\left(1 / R_{X}+1 / R_{N}\right) \mathcal{R}\right\}}, \\
& S_{g_{m_{1}}}^{\omega_{0}}=\frac{g_{m_{1}}\left\{g_{m_{2}}-\left(1 / R_{X}+1 / R_{N}\right)\right\}}{2\left\{g_{m_{1}} g_{m_{2}}+\left(1 / R_{X}+1 / R_{N}\right) \mathcal{R}\right\}}, \\
& S_{g_{m_{2}}}^{\omega_{0}}=\frac{g_{m_{1}} g_{m_{2}}}{2\left\{g_{m_{1}} g_{m_{2}}+\left(1 / R_{X}+1 / R_{N}\right) \mathcal{R}\right\}} .
\end{aligned}
$$

From the above mentioned sensitivity values, it is easy to figure out that all the active and passive sensitivities are no more than half in magnitude.

\section{Frequency Stability}

Using the definition of the frequency stability factor $S^{F}$ as given in [5], $S^{F}=\left.(d \phi(u) / d u)\right|_{u=1}$ (where $u=\omega / \omega_{0}$ is the normalized frequency and $\phi(u)$ represents the phase of the open-loop transfer function of the oscillator circuit), with $C_{1}=C_{2}=C, g_{m_{1}}=1 / R_{1}=g_{m}$, and $g_{m_{2}}=n g_{m}$; the $S^{F}$ of the proposed oscillator is found to be $2 \sqrt{n}$. Therefore, very good frequency stability is obtainable by selecting larger value of $n$. 


\section{Simulation Results}

To confirm theoretical analysis, the proposed ECMSO was simulated using CMOS VDTA from [15]. Power supply voltages were taken as $V_{\mathrm{DD}}=-V_{\mathrm{SS}}=0.9 \mathrm{~V}$ and $I_{B 1}=$ $I_{B 2}=I_{B 3}=I_{B 4}=150 \mu \mathrm{A}$ biasing currents are used. The transistor aspect ratios are taken from [15]. The passive elements of the configuration were selected as $C_{1}=C_{2}=$ $0.01 \mathrm{nF}$ and $R_{1}=1.7 \mathrm{k} \Omega$. The transconductances of VDTA were controlled by bias currents. PSPICE generated output waveforms indicating transient and steady-state responses are shown in Figures 3(a) and 3(b), respectively. These results, thus, confirm the validity of the proposed configuration. The total harmonic distortion (THD) of the proposed oscillator is found to be $2.66 \%$ (Figure 4). A comparison with other previously known ECMSOs using single active building block has been given in Table 1. Figure 5 shows the frequency responses of the BP and LP filters obtained from the proposed configuration. From Figures 6,7 , and 8 , it is clear that the two currents are in quadrature.

As a sample example, Figure 8 shows that the two currents are in quadrature and the measured value of phase shift between two waveforms is $=89.047^{\circ}$.

\section{Concluding Remarks}

A new application of VDTA has been introduced in the realization of a novel ECMSO. In oscillator mode, the circuit offers (i) independent control of frequency of oscillation and condition of oscillation, (ii) use of grounded capacitors which are attractive from the viewpoint of IC implementation as well as eliminating/accommodating parasitic capacitances, (iii) ready availability of explicit current-mode output, (iv) low active and passive sensitivities, and (v) a very good frequency stability. In filter mode, the structure realizes LP and BP filter responses simultaneously with independent control of $\omega_{0}$ and BW. In third mode of operation, the circuit offers quadrature current-mode outputs. The validity of the proposed configuration in various modes of operation has been established by the PSPICE simulations.

\section{Acknowledgment}

The authors gratefully acknowledge Professor Dr. Raj Senani, the Head of the Division of Electronics and Communication Engineering, and the Director of NSIT, New Delhi, for useful discussions/suggestions.

\section{References}

[1] C. Toumazau, F. J. Lidgey, and D. G. Haig, Analogue IC Design: The Current-Mode Approach, Peter Peregrinus Limited, London, UK, 1990.

[2] D. R. Bhaskar and R. Senani, "New FTFN-based groundedcapacitor SRCO with explicit current-mode output and reduced number of resistors," AEU-International Journal of Electronics and Communications, vol. 59, no. 1, pp. 48-51, 2005.
[3] R. Senani, "New types of sine wave oscillators," IEEE Transactions on Instrumentation and Measurement, vol. 34, no. 3, pp. 461-463, 1985.

[4] R. Senani and D. R. Bhaskar, "Single op-amp sinusoidal oscillators suitable for generation of very low frequencies," IEEE Transactions on Instrumentation and Measurement, vol. 40, no. 4, pp. 777-779, 1991.

[5] D. R. Bhaskar and R. Senani, "New CFOA-based singleelement-controlled sinusoidal oscillators," IEEE Transactions on Instrumentation and Measurement, vol. 55, no. 6, pp. 20142021, 2006.

[6] J. J. Chen, C. C. Chen, H. W. Tsao, and S. I. Liu, "Currentmode oscillators using single current follower," Electronics Letters, vol. 27, no. 22, pp. 2056-2059, 1991.

[7] M. T. Abuelmatti, "Grounded-capacitor current-mode oscillator using single current follower," IEEE Transactions on Circuits and Systems I, vol. 39, no. 12, pp. 1018-1020, 1992.

[8] M. T. Abuelma'Atti and H. A. Al-Zaher, "Current-mode sinusoidal oscillators using single FTFN," IEEE Transactions on Circuits and Systems II, vol. 46, no. 1, pp. 69-74, 1999.

[9] S. S. Gupta and R. Senani, "Grounded-capacitor currentmode SRCO: novel application of DVCCC," Electronics Letters, vol. 36, no. 3, pp. 195-196, 2000.

[10] C. M. Chang, B. M. Al-Hashimi, H. P. Chen, S. H. Tu, and J. A. Wan, "Current mode single resistance controlled oscillators using only grounded passive components," Electronics Letters, vol. 38, no. 19, pp. 1071-1072, 2002.

[11] R. Senani and R. K. Sharma, "Explicit-current-output sinusoidal oscillators employing only a single current-feedback opamp," IEICE Electronics Express, vol. 2, no. 1, pp. 14-18, 2005.

[12] V. Aggarwal, S. Kilinç, and U. Çam, "Minimum component SRCO and VFO using a single DVCCC," Analog Integrated Circuits and Signal Processing, vol. 49, no. 2, pp. 181-185, 2006.

[13] U. Çam, A. Toker, O. Çiçekoğlu, and H. Kuntman, "Currentmode high output impedance sinusoidal oscillator configuration employing single FTFN," Analog Integrated Circuits and Signal Processing, vol. 24, no. 3, pp. 231-238, 2000.

[14] D. Biolek, R. Senani, V. Biolkova, and Z. Kolka, "Active elements for analog signal processing: classification, review, and new proposals," Radioengineering, vol. 17, no. 4, pp. 1532, 2008.

[15] A. Yeşil, F. Kaçar, and H. Kuntman, "New simple CMOS realization of voltage differencing transconductance amplifier and its RF filter application," Radioengineering, vol. 20, no. 3, pp. 632-637, 2011.

[16] D. Prasad, D. R. Bhaskar, and A. K. Singh, "Electronically controllable grounded capacitor current-mode quadrature oscillator using single MO-CCCDTA," Radioengineering, vol. 20, no. 1, pp. 354-359, 2011. 

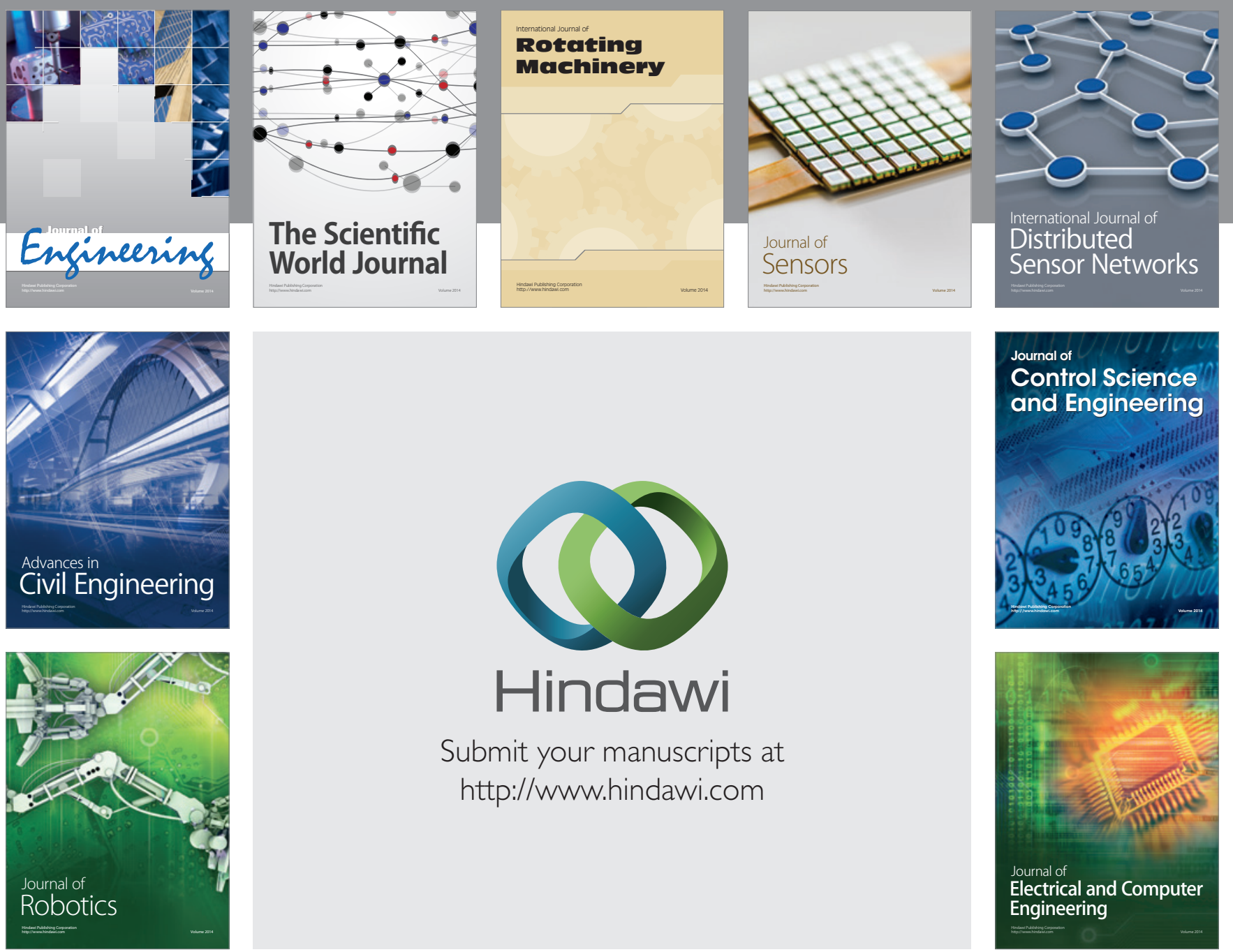

Submit your manuscripts at

http://www.hindawi.com
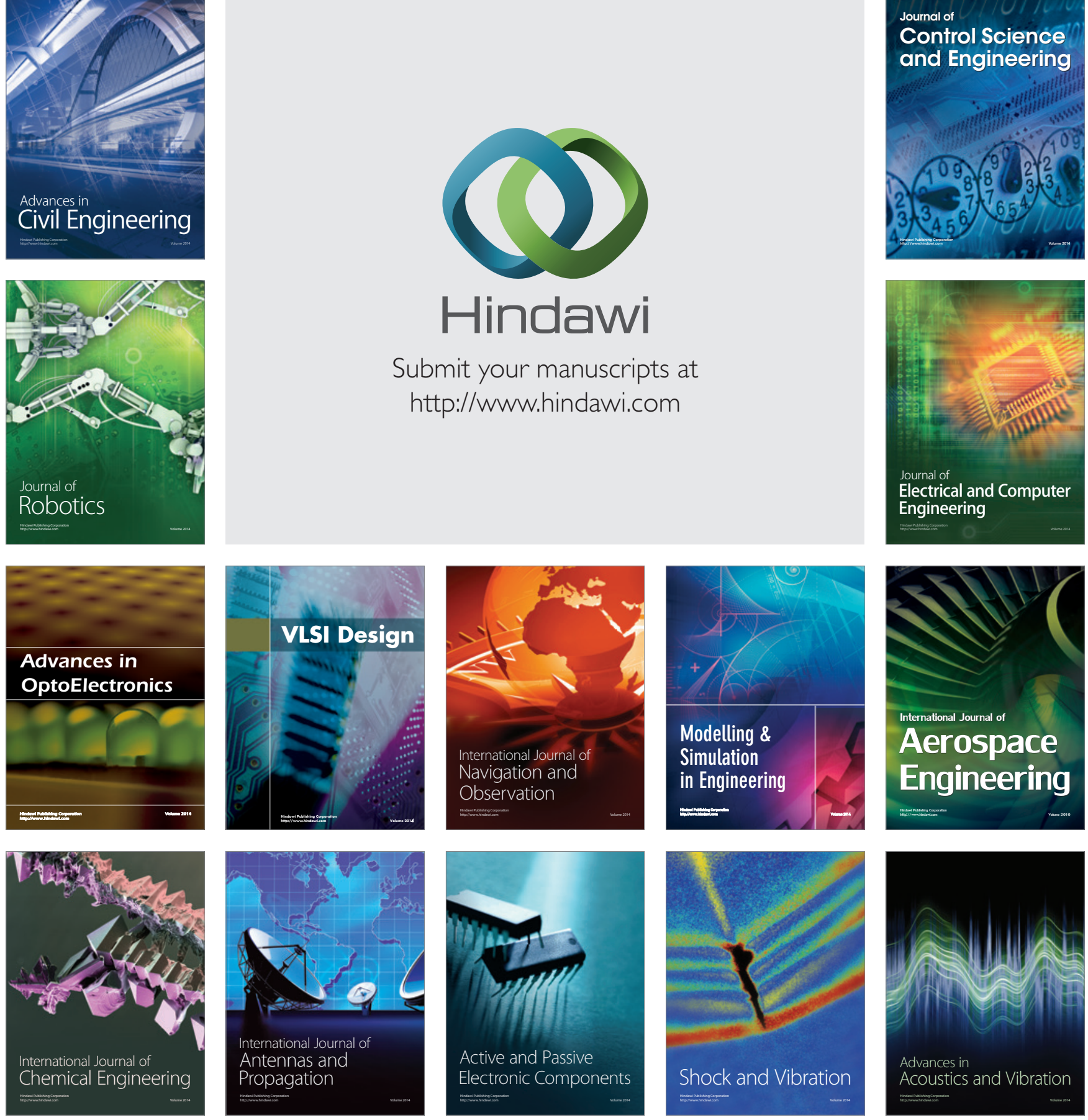